\title{
Geometrías del asentamiento y de evolución de las estructuras compositivas de la iglesia de Po- zos. La Cabrera Alta. (León-España)
}

\author{
Gaspar FERNÁNDEZ SAN ELÍAS, Natalia MONTES FERNÁNDEZ, \\ Benito De CElis CARRILlo, Francisco de Paula Montes Tubío \\ Universidad de León - Universidad de Córdoba
}

\begin{abstract}
RESUMEN. Se trata de un trabajo de investigación sobre la arquitectura religiosa de Pozos (La Cabrera Alta), realizado mediante la metodología más adecuada: el dibujo, el análisis tipológico y su complementación con la documentación histórica y bibliográfica pertinente. Ha exigido medir, comparar, analizar sus unidades elementales en relación a otras arquitecturas vecinales en la comarca, haciendo evidente su geometría y los mecanismos de su restitución gráfica evolutiva desde su fundación, en el s XII, hasta derivar en la articulación de la forma arquitectónica resultante actual. Es una edificación que parte de estructuras muy simples a modo de invariantes formales, de autor/es desconocidos, autoconstruida y vernácula, sin arquitectos, pero asentada en la funcionalidad y tradiciones muy arraigadas, que ganan complejidad mediante el enriquecimiento de otras existentes y adición de elementos.

Palabras clave: armadura de cubierta, armadura ochavada, gualderas ataujeradas, limabordón, pechina, pizarra, esquistos, piedra de arenisca, mampostería, arcos formeros, arco triunfal, arco de medio punto, epigráfico, pórtico, portada románica, portada barroca, bocel, dovela, clave, chambrana, espadaña.
\end{abstract}

RÉSUMÉ. Il s'agit d'un travail de recherche sur l'architecture religieuse de Pozos (La Haute-Cabrera), réalisé en utilisant la méthodologie la plus appropriée : le dessin, l'analyse typologique qui se complète par la documentation historique et la bibliographie pertinente. Tout cela nous a exigé de mesurer, comparer, analyser les unités élémentaires pour rendre l'évidence de sa géométrie et les mécanismes de sa restitution graphique évolutive, depuis sa constitution au XII ème siècle, pour en arriver à l'articulation de la forme architectonique actuelle. C'est une construction qui part de structures très simples en guise d'invariantes formelles, d'auteur (s) inconnus, autoconstruite et nationale, sans architecte, mais établie sur la fonctionnalité et sur des traditions très enracinées dont la complexité augmente avec l'enrichissement d'autres existantes et l'adition d'éléments.

Mots clé: charpente, charpente octogonale, flasques, arête, pendentif, ardoise, schistes, grès, maçonnerie, arcs formerets, arc triomphal, arc en plein cintre, épigraphique, portail, portail roman, portail baroque, tore, douelle, clef, lambris, chambranle, clocher à jour.

\section{INTRODUCCIÓN}

Es Pozos la población más meridional de la Cabrera Alta y tenemos constancia de su existencia al menos desde las primeras décadas del siglo XII, pues en el año 
1115 se produce la donación de una heredad al obispo de Astorga en su término ${ }^{1}$.

Como la mayoría de los pueblos de la Cabrera el poblamiento se extiende en el medio de una ladera montañosa. La iglesia parroquial, bajo la advocación de los santos Cosme y Damián, se levanta en el barrio de Oteiro, ligeramente aislada de la mayor parte del pueblo.

La intención del presente trabajo es reconstruir la evolución geométrica de la historia de su arquitectura religiosa a partir de los elementos más importantes $\mathrm{y}$, sin duda, más desconocidos de su pasado, que fueron relegados de cualquier estudio $o$ proyección planimétrica y que más han intervenido en la organización social y espacial de la zona.

\section{METODOLOGIA}

Para la elaboración del presente trabajo de investigación nos hemos apoyado en tres pilares fundamentales: fuentes documentales, trabajo de campo y trabajo de gabinete.

\subsection{Investigación histórica}

Se ha fundamentado en una rigurosa y paciente labor de investigación histórica sobre la comarca apoyada fundamentalmente, ante la falta de estudios, en el estudio de fuentes documentales hasta ahora inéditas que nos han permitido conocer de forma científica la evolución de la mayoría de las fábricas de los edificios religiosos de La Cabrera Alta. Para poder hacernos una idea de estos edificios y de su interrelación con el paisaje es necesario conocer su historia y dada la falta de estudios históricos de la zona, nos hemos servido de documentación guardada en los archivos siguientes:

- El Archivo Diocesano de Astorga (A.D.A.). La consulta de libros de fábrica de las iglesias que se conservan en la citada institución (Cunas, Villar del Monte, Iruela,...) junto a los libros de visitas a las parroquias y a los protocolos de notarios del siglo XVI han sido fundamentales para ayudarnos en la interpretación de los edificios religiosos.

- La documentación de estas fuentes se ha visto completada con escrituras notariales custodiadas en el Archivo Histórico Provincial de León, en la Sección de Protocolos de Ponferrada, Astorga y La Bañeza. Se trata de algunos contratos de obras entre los comitentes (párroco y mayordomo) y los artesanos y maestros de obras (canteros y carpinteros).

- Bibliografía relacionada con estas temáticas y que se referencia a pie de página.

- Asimismo, ha existido una información oral, dado que los párrocos, presidentes de núcleos poblaciones, personas mayores... aún recuerdan concreciones sobre los actuales.

\subsection{Trabajo de campo}

El segundo pilar lo ha constituido la visita y análisis en directo. Un largo y detallado trabajo de campo mediante la consideración del edificio como propia fuente de datos, el reconocimiento del terreno, el levantamiento de planos topográficos, las mediciones (formado por grupos tres personas) y determinación de las coordenadas geográficas del edificio objeto de estudio.

Para la realización del levantamiento topográfico se ha empleado el GPS, técnica suficientemente precisa para el cartografiado de la zona de nuestro trabajo. Además se cuenta con la ventaja que los levantamientos obtenidos están georreferenciados, es decir que una vez obtenidas las coordenadas en el sistema de referencia de satélites, el WGS84, se pueden transformar a

\footnotetext{
${ }^{1}$ A.D.A. Tumbo Negro, f. 40(v).
} 
coordenadas UTM².

Una vez obtenidas las coordenadas UTM, el trabajo es directamente superponible a cualquier cartografía oficial que se disponga de la zona.

La precisión que necesitamos será función de la escala a la que se deseen los resultados, esto es $0,2 \mathrm{~mm}$ por el denominador de la escala del plano, así para la escala 1:5.000 será de $1 \mathrm{~m}$ o mejor. De lo expuesto hasta ahora, podemos deducir que el método de posicionamiento que se ajusta como mínimo a priori a las necesidades de nuestro trabajo, es el GPS diferencial trabajando en RTK (Real Time Kinematic).

El equipo empleado en la toma de datos es un GPS Topcon Hiper + que ofrece comunicación inalámbrica y una avanzada antena UHF que facilita el trabajo en modo RTK y multiplica el alcance de radio sin disminuciones de la calidad señales GPS.

Se tomaron los puntos característicos del terreno, grabando los datos en la libreta electrónica Topcon Fc- 1000, una vez realizado el trabajo de campo se volcaron los datos al ordenador, elaborando la cartografía base de la zona.

Los planos de detalle del edificio se han realizado con la Estación Total Pentax RN-326. Esta Estación tiene la ventaja de poder realizar mediciones de distancia sin prisma, opción que hemos utilizado para realizar el levantamiento de las fachadas del edificio. Las mediciones dentro del edificio se han realizado mediante un medidor laser.

Esta captura de información gráfica, realizada "in situ" comprende tres aspectos: croquis, acotaciones y fotografías. Los cro-

-

${ }^{2}$ F. MANZANo Agugliaro, et al., Cartografiado de Parcelas de Naturaleza rústica, Universidad de Almería, 1996. quis permiten reconocer la geometría precisa y constituyen el soporte del dimensionado que permite la realización del posterior grafismo planimétrico.

En la primera fase del Levantamiento Topográfico con Estación Total debemos establecer una red de bases que englobe la zona de trabajo de manera que desde ellas sea visible toda la superficie a levantar. Las bases deben cumplir una serie de condiciones ${ }^{3}$ :

1. Estabilidad Dimensional: No variar de forma o tamaño.

2. Estabilidad Material: Elegir materiales resistentes a agentes externos.

3. Estabilidad Espacial: Situarlos en zonas de terreno estable y fuera de las zonas más transitadas.

4. Materializarlos de forma fina, precisa e inequívoca de tal manera que su forma sea lo más parecida a un "punto".

5. Fácilmente estacionable: Que el aparato utilizado en el levantamiento al colocarlo sobre el punto se pueda realizar de manera rápida y cómoda.

6. Observable desde otras bases de la zona.

7. Fácilmente localizable: Que pueda ser encontrada con rapidez, para lo que deberá estar adecuadamente "reseñada".

Además de estas consideraciones generales sobre las bases del levantamiento hemos de tener presente que el proceso de cálculo y observación de las mismas ha de cumplir con unas precisiones mínimas que nos vendrá determinada por las precisiones de métodos e instrumentos de trabajo y de la escala final del plano.

Una vez establecida la red de bases, tomaremos los puntos más significativos del terreno por el método de Radiación.

\footnotetext{
${ }^{3}$ M. CRESPO AlONSO, Elementos de señalización en Topografía. Topografía y Cartografía, Vol. IX- № 49, Marzo-Abril, Colegio Oficial de Ingenieros Técnicos en Topografía, Madrid, 1992.
} 
La radiación es un método Topográfico que permite determinar coordenadas $(X, Y, Z)$ desde un punto fijo del que conocemos las coordenadas. Para dar coordenadas a los puntos del Levantamiento, se estaciona la E.T. en una de las bases de la red principal $(\mathrm{O})$ y desde ella se visan los puntos deseados.

Los datos de campo que se adquieren con la E.T. mediante el método de radiación son:

- Lecturas acimutales a la referencia y a los puntos radiados.

- Lecturas cenitales.

- Distancias.

- Altura de instrumento.

- Altura del prisma.

- Código del punto radiado.

Las E.T., disponen de programas internos que transforman estos datos en coordenadas $(X, Y, Z)$, en el sistema de representación elegido.

Las coordenadas son grabadas en la memoria interna de la E.T. para posteriormente su volcado al PC en un fichero de formato ASCII. El tratamiento posterior de las coordenadas se realizará de igual forma que los datos obtenidos con el GPS.

Para el levantamiento de las fachadas se ha utilizado la medición de distancias sin prisma y con puntero visible, la toma de datos se ha realizado desde las bases del levantamiento, con este método se consiguen vistas y proyecciones con las dimensiones reales de los objetos que la forman, exentas de cualquier deformación o distorsión, sin que sea necesario un complicado tratamiento de datos posterior en Gabinete.

\subsection{Trabajo de Gabinete}

Una vez tomados los datos de campo para la obtención de la cartografía de detalle, realizamos en gabinete el tratamiento y procesamiento de estos datos.
El software utilizado en todo este proceso fue los módulos de Edición de Coordenadas y Modelo Digital del Terreno (MDT) del programa informático Protopo V6.

\subsubsection{Fases del trabajo de gabinete:}

1. Volcado de los datos tomados en campo del GPS al ordenador, obteniendo un fichero de puntos con coordenadas X, Y, $\mathrm{Z}$.

2. Dibujo de los puntos del taquimétrico y de las líneas de rotura del terreno, dibujo que realizaremos a partir de la codificación efectuada en campo, serán líneas de rotura los caminos, carreteras, arroyos, vaguadas, divisorias, etc. En esta fase también dibujaremos los elementos que no siendo líneas de rotura nos sirvan para tener una representación del terreno lo más fiel a la realidad.

3. Creación del modelo digital en 3D mediante triangulación entre los puntos representativos del relieve, teniendo en cuenta las líneas de rotura y zonas de exclusión.

4. Obtención de las curvas de nivel interpolando las cotas de los lados de los triángulos del modelo digital según la equidistancia seleccionada, suavizando posteriormente los vértices de las mismas y rotulando los textos de las cotas en las curvas directoras.

5. Edición final del plano, con el dibujo de los elementos representativos tomados en el campo, inserción de la simbología, sombreado, cuadrícula de coordenadas y completando la información del margen como la escala gráfica, leyendas, etc.

El volcado de puntos de la toma de datos de las fachadas se ha realizado de manera análoga a la anterior, para el tratamiento posterior de los datos se ha utilizado el programa Autocad de Autodesk.

Las representaciones gráficas, para su rigor métrico, se han llevado a efecto, previo conocimiento de los datos y la topo- 
grafía, con diversas aplicaciones de diseño gráfico, fundamentalmente autocad y posteriormente, para la ilustración conveniente, se ha operado con illustrator. Asimismo se ha considerado conveniente recurrir a la representación de su perspectiva explosionada en corte al cuarto que facilita la observación, transmisión y compresión geométrica profunda de la edifición propuesta.

La documentación fotográfica aporta aspectos constructivos debido a la materialidad física del edificio: materiales, conocimientos relativos a las técnicas usadas, sistemas constructivos, datación edificatoria, informaciones relativas a un cierto movimiento arquitectónico, características destacables...

Las composiciones fotográficas, para la elaboración de las panorámicas del edificio, se han realizado con photoshop.

\section{LA ARQUITECTURA RELIGIOSA EN LA CABRERA ALTA}

El estudio de la iglesia de Pozos debe encuadrarse y estudiarse desde el entorno de uno de los valores patrimoniales más notables, que conforman el paisaje artístico y cultural de la comarca de La Cabrera Alta, que es sin duda alguna su arquitectura religiosa. Es la más monumental de todas en una comarca donde nunca ha habido grandes señores -entiéndase nobles- que viviesen en el país y construyesen sus casonas o palacios, ya que todos los dueños y señores de estas tierras, fuesen reyes, nobles o eclesiásticos durante todo el Antiguo Régimen, nunca residieron en ella.

Por otro lado, las limitaciones y los condicionamientos naturales y humanos que se dan en esta comarca hacen de ella, más que en ninguna otra región de Castilla y León, que manifieste soluciones auténticamente populares. Alejadas estas edificaciones de las corrientes cultas que recorren Europa, encuentran en lo popular la razón de su propia existencia y solamente se servirán de lo culto para modernizarlas, pero desde un punto de vista intrascendente y completamente tangencial.

3.1. Morfologías constructivas y arquitectónicas

\subsubsection{Las cubiertas interiores}

Comenzaremos nuestro análisis por las cubiertas interiores dado que no sólo posibilitan la creación de los espacios al ayudar a definirlos y cerrarlos, sino que en gran medida esos espacios están determinados por el tipo de cubierta utilizado: tamaños, luces, grosor de los muros..., etc.

Por lo que se refiere a la arquitectura religiosa de carácter popular generalmente suelen predominar las cubiertas leñosas sobre las pétreas, ocupando estas últimas un lugar destacado. Así en la vecina comarca del Bierzo, son las más habituales, si bien existen también numerosos ejemplos de cubiertas de pizarra ${ }^{4}$. Sin embargo, en La Cabrera Alta, los edificios religiosos cubren todos sus espacios: capillas mayores, laterales, sacristías, pórticos y cabildos,... con armaduras de cubierta, y solamente dos espacios se han servido de bóvedas pétreas a lo largo del tiempo: uno el presbiterio de la iglesia parroquial antigua de Cunas, en la actualidad arruinada; y el otro el presbiterio de la parroquial de Manzaneda. O sea, que en este aspecto tan esencial en la arquitectura religiosa rural nos encontramos ya con un elemento particular y casi podíamos decir exclusivo ${ }^{5}$.

Han sido el sistema de techumbres más utilizado en toda Europa, desde los tiempos más remotos hasta épocas relati-

\footnotetext{
${ }^{4}$ V. FERNÁNDEZ VÁZQUEZ, Arquitectura religiosa en El Bierzo. Siglos XVI-XVIII, 2 Vols, Ponferrada, 2001.

${ }^{5}$ No se contabiliza aquellos templos que conservando la armadura primitiva en mal estado la forraron con techos de cañizo enyesado en el siglo XX.
} 
vamente recientes. Se conoce muy bien su situación, técnica y evolución desde la Edad Media $^{6}$. En La Cabrera son casi las únicas que se llegaron a utilizar y todas son muy sencillas, no hay ningún artesonado, ninguna utiliza como elementos decorativos lazos, mocárabes, chellas... Es la solución utilizada tanto en los edificios parroquiales como en las ermitas y santuarios; desde la capilla mayor al presbiterio, y sin gran variedad en los tipos, se repiten con asiduidad, e incluso en edificios de la misma localidad, las mismas soluciones, sobre todo cuando se fabrican al mismo tiempo, y en el caso de hacerse en momentos distintos, en los contratos se especifica que se haga como la de "tal" iglesia.

Los factores que han influido en el predominio casi absoluto de las armaduras de cubierta en La Cabrera son las siguientes: en primer lugar los condicionamientos económicos, dado que las de obra son mucho más caras. En segundo está la tradición, desde la Edad Media ha sido la solución más recurrente en la zona. En tercer lugar está la abundancia de madera y de carpinteros expertos en su trabajo, dado que ante el aislamiento y las comunicaciones tan difíciles que tenían los cabreireses tuvieron que aprender a ser autosuficientes en muchos aspectos, y este fue uno de ellos. En cuarto lugar y en relación con el anterior, no debemos de olvidar que todos los concejos tenían dehesas y montes comunales de los que se podían servir gratuitamente, cogiendo la madera que necesitasen para sus hogares y la madera para sus casas o para sus edificios

\footnotetext{
${ }^{6}$ No hay grandes diferencias entre las armaduras medievales y las modernas. En la arquitectura culta una diferencia notable era que las medievales se solían pintar completamente, mientras en la Edad Moderna no, pero en la arquitectura religiosa popular, se pintaban tanto en la Edad Media como en la Edad Moderna, ya que al no tener grandes relieves tallados y decorados recurrían a pintarlas en su totalidad porque era mucho más económico.
}

comunes, como los religiosos, por lo cual en gran medida la materia prima podía resultarles gratuita. En quinto lugar están las pequeñas dimensiones de las iglesias y especialmente de los espacios a cubrir, facilitaba que se cubriesen con madera. $Y$ en último lugar está la inexistencia en la zona de conventos, que con sus fábricas, muchas de ellas pétreas, podían servir de ejemplo a seguir e imitar, favoreció que ni los concejos ni párrocos se sintieran atraídos por ellas.

\subsubsection{Tipologías de cubiertas}

Martínez Caviró ${ }^{7}$, Miguel Fernández $\mathrm{Cabo}^{8}$ y Enrique Nuere ${ }^{9}$ han establecido complejas y completas clasificaciones de las armaduras de cubierta en función de distintas variables. En nuestro trabajo hemos seguido la clasificación establecida por Miguel Fernández Cabo para las tipologías de la provincia de León, en función de aspectos:

a. Formales: armaduras de $n$ aguas (de 1 agua, llamadas de colgadizo, de 2 y de 3 ó 4 aguas); de $n$ paños $(1,2,3,5$ ó 7 paños); abovedadas y de techos planos.

b. Constructivos: de pares (de parhilera y de par y nudillo); de limas (de limabordón y moamares); de alfarjes, enyesadas y de armazón, pudiendo ser éste: artesonado, ataujerado, apeinazado, entablado, de mocárabes o llano.

${ }^{7}$ B. MARTíNEZ CAVIRÓ, «Carpintería de lo blanco» en A. BOnEt CorreA, (Coord.), Historia de las Artes Aplicadas e Industriales en España, Madrid, 1982, pp. 247-259. «Sobre las armaduras de madera en el arte mudéjar toledano», Actas del XXII Congreso Internacional de Historia del Arte, Granada, 1973, tomo II, pp. 247269. «Hacia un corpus de la carpintería de lo blanco», Actas II Simposio Internacional de mudejarismo, Teruel, 1982, pp. 125-129.

${ }^{8}$ M. FERNÁNDEZ CABO, Las armaduras de cubierta, León, 1997.

${ }^{9}$ E. NUERE, La carpintería de armar española, Madrid, 1990. 
b.1. Entre las armaduras de pares, dadas las condiciones climatológicas de La Cabrera, con una pluviosidad superior a $1.500 \mathrm{~mm}$., son las más utilizadas ya que conllevan cubiertas que tengan pendientes pronunciadas. Los pares por la parte superior se clavan en la hilera y en la inferior, sobre el estribo. Generalmente, este tipo de armadura se protege con una techumbre sobre la que va el tejado, pero en La Cabrera en más de una ocasión, sobre todo en las cubiertas del cuerpo de la iglesia, nos encontramos que el tejado va directamente sobre la armadura.

Dentro de este tipo de armaduras de pares hay las siguientes variantes:

i. De parhilera. Son las más sencillas. Con ellas se cubren los cuerpos de la nave que tienen poca luz. En su fabricación intervienen la hilera, una viga de madera colocada horizontalmente por debajo del lomo de la cubierta a dos aguas en la que convergen las cabezas de los pares, y los pares o alfardas, los maderos oblicuos que forman la pendiente de la armadura, los faldones, y que apoyan en la hilera por la parte superior $y$ en el estribo por la inferior. Es frecuente que lleven pendolón, pero no en la Cabrera.

ii. De par y nudillo. En realidad es una variante de la armadura de parhilera. Este tipo se utiliza en cubiertas a dos aguas: cuerpo de la nave. Consiste en situar entre dos pares opuestos un nudillo, que generalmente va arriostrado a dos tercios de su altura. Una de sus partes es el almizate, también denominado harneruelo, que está formado por la sucesión de los nudillos, con su correspondiente tablazón, y la otra, las gualderas o faldones, que son los costados. b.2. De limas. Es uno de los tipos más utilizados para cubrir espacios cuadrados como los de los presbiterios o rectangulares pequeños, como capillas laterales y en raras veces sacristías. En líneas generales se trata de una armadura de pares, de parhilera y de par y nudillo que al presentar más de dos faldones y llevar unas limas en su intersección, llega a fijar unas diferencias formales respecto a las de parhilera y par y nudillo.

Se distinguen dos variedades, en función del número de limas: limabordón, con una lima, y moamar, con dos. Las de limabordón pueden ser armaduras de limabordón pares (ABP) y armaduras de limabordón nones $(\mathrm{ABN})$. Las primeras, cuando el número de pares es par en los faldones y ningún nudillo alcanza el nabo central; y las segundas, cuando llevan un número impar de pares y uno de los nudillos alcanza el nabo central. Las dos llevan en el centro un almizate, decorado con un pinjante en forma de florón o piña y en La Cabrera solamente se llegaron a construir las primeras: las de limabordón. Dentro de las de este tipo se suelen diferenciar -en otras partes, no es el caso de La Cabrera, donde la variedad es poco recurrente- a varios modelos:

i. De cuatro faldones sin almizate: las más sencillas, están formadas por cuatro faldones, con limas en su intersección que converge en el nabo central.

ii. De cuatro faldones y almizate, las más frecuentes son las de limabordón nones y como suele ser habitual se utilizan en capillas mayores.

iii. De tres faldones, al tratarse de armaduras sencillas y muy adaptables a espacios rectangulares se usan para cubrir el cuerpo de las iglesias parroquiales. 
b.3. De colgadizo o molinera. Son con mucho las más sencillas. Hay autores como Enrique Nuere que no las consideran como armadura al no ejercer los pares ninguna presión sobre los muros, condición indispensable para que sea una cubierta de armadura. Se aplican para cubrir los espacios menos nobles: sacristías, naves laterales, chapiteles de las espadañas y cabildos o pórticos. En todos los casos, los pares apoyan en la carrera y en la jácena, que va sobre las zapatas.

\subsection{Cubiertas exteriores.}

En la comarca el único tipo de cubierta que hemos encontrado para los edificios parroquiales es el de pizarra. En los libros de fábrica o contratos no nos ha aparecido ninguna referencia a cubiertas con teja, posiblemente por ser más cara, ni a las cubiertas de tipo vegetal, y esto sí que ha llamado mucho nuestra atención, sobre todo en una comarca en la que el centeno ha sido el cultivo "rey", en una comarca donde hasta el día de hoy, las cubiertas de cuelmo están presentes en cientos de pajares y cuadras, como podemos observar en Corporales o Villar del Monte, y que incluso en el XVI servía para cubrir la torre del homenaje del castillo de Peñaramiro.

Si realmente ha sido así, si los edificios religiosos no se cubrieron con cuelmo, suponemos que se deba al peligro de los incendios, ya que durante siglos las cubiertas vegetales fueron utilizadas en regiones de su entorno.

\subsection{Plantas}

Todos los edificios religiosos de La Cabrera Alta reducen los tipos de plantas, a dos básicos: rectangular y de cruz latina.

\subsection{Vanos}

La altitud, la dureza del clima y las directrices tridentinas a partir del último tercio del XVI y hasta finales del XVIII, condicionará la presencia de los vanos de las iglesias parroquiales. La mayoría de los templos, a causa de las condiciones climatológicas, tendrán su entrada en el lienzo del sur para que penetre la luz y el calor del sol.

En cuanto a los ventanales todos suelen ser adintelados y abocinados y la mayoría se abren en el lienzo del sur tanto en el cuerpo, como en el transepto si lo tiene, como en el presbiterio y en la sacristía.

Tras el concilio de Trento y, sobre todo a partir de 1572, se recomienda que la luz solar ilumine bien el interior del presbiterio, por eso a partir de la fecha señalada los visitadores de la diócesis suelen insistir no solo en reedificar y hacer mayor la capilla mayor sino en "rasgar" las ventanas existentes haciéndolas mayores para potenciar el altar mayor y para que se convierta en el referente espacial y cultual.

\subsection{Portadas}

La mayoría de las portadas de los edificios religiosos de la Cabrera Alta son sencillas. La disponibilidad de pocos recursos de sus fábricas condiciona su carácter. Siempre las más notables son las de la entrada principal ya que todas las demás, sacristías, almacenes o panera, son muy sencillas. Todas las principales están situadas al sur y protegidas, siempre, por un pórtico mixto: cabildo y/o portal fondero.

\subsection{Elementos sustentantes}

Muros, pilares y pies derechos son los únicos elementos sustentantes de la arquitectura de La Cabrera Alta. Los muros son de carga y reciben el peso de las armaduras, techumbres y tejado, y dado que en la mayoría de los casos las primeras son leñosas, apenas generan grandes presiones por lo que no hay necesidad de hacerlos de mucho grosor. 
El pilar es en el interior de los templos el único soporte de los arcos formeros, los que separan las naves. Son sencillos, nunca compuestos y la sección suele ser rectangular. Solo en la iglesia de Pozos muestran una sección circular. Están construidos siempre en sillar al igual que los arcos en arenisca, y apenas presentan adornos. Su ejecución suele ser bastante tosca, a no ser en las parroquiales de Corporales y Pozos.

En los pórticos se sirven tanto de pilares como de pies derechos, estos a veces con zapatas de madera.

\subsection{Espadañas}

A falta de torres, en la Cabrera Alta todos los edificios religiosos utilizan espadañas para colocar las campanas. Sencillas y triangulares las del XVI y XVII; las del XVIII alcanzan una mayor envergadura, se hacen más complejas y suelen tener tres vanos, si bien el superior es para un esquilón pequeño. Su silueta triangular, que se impone visualmente sobre el resto de las dependencias del templo y sobre todo el caserío, se convierte en un referente significativo del paisaje. Estas espadañas de tipo parietal al ir sobre un muro o pared de su fábrica, en esta comarca siempre en el occidental, son propias de fábricas humildes y con pocas rentas. Son significativas las majestuosas panorámicas del paisaje cabreirés que se pueden observar desde las mismas.

El sonido de sus campanas ha marcado el ritmo de la vida y de la muerte de generaciones y generaciones de cabreireses, con sus toques del alba, del ángelus y de las ánimas. Marcaron el ritmo diario de las gentes: el levantarse, dejar la faena de trabajo, acostarse; al mismo tiempo que invita a los fieles creyentes a la oración. El toque de difuntos, los de aviso para servicios litúrgico (la misa, el rosario, las procesiones); los profanos, con sus toques de nublado, para alejar las tormenta; de concejo, para reunir a los vecinos en concejo abierto de vecinos; de facendera, para realizar faenas comunales: limpieza de los caminos, arreglo de los puentes...; para avisar de incendios o de un peligro. Su voz servía también para anunciar los grandes acontecimientos políticos, sociales y militares de la monarquía: nacimientos de príncipes, infantes, matrimonios de la realeza, victorias...

Las espadañas no solo cobijaban en sus bocas a las campanas, sino también a los relojes de sol del concejo. Pensamos que todas las iglesias parroquiales tuvieron el suyo. Se montaba sobre arenisca o pizarra y se situaban por lo general en uno de los laterales de la espadaña. Actualmente se conservan varios: en la iglesia de Quintanilla, en la de Pozos,... Posiblemente todos sean del siglo XVIII.

La escalera de acceso a las espadaña desemboca en una galería que se cubre con un chapitel de madera que la protege.

\subsection{Portales, pórticos y cabildos}

Son galerías con diversos tipos de armaduras que apoyan en pies derechos o pilares y que se adosan a la fachada de los templos parroquiales, ermitas y santuarios. Actúan como espacios adjuntos a los edificios religiosos y cumplen las siguientes funciones:

- Religiosa: Al preservar las puertas de acceso generan un espacio de transición entre el exterior y el interior en el que reside la misma divinidad y antiguamente cuando los feligreses se acercaban a él se preparaban para entrar en el recinto sagrado guardando silencio o bajando la voz en señal de respeto.

- Física: Resguardan la puerta y la portada de las inclemencias del tiempo.

- Social: En los pueblos en los que no había ningún lugar de reunión común, se convertían en el lugar donde se celebraban las sesiones de concejo abierto. 
- Entretenimiento: Era el escenario donde tenían lugar las danzas los días festivos.

- Ocio: Eran un lugar de encuentro y reunión especialmente los días de invierno, ya que al estar orientado hacia el sur gozaban de unas mejores temperaturas.

Portales, pórticos y cabildos responden a tres conceptos distintos, aunque cumplan funciones semejantes y en algunas ocasiones se designe con el mismo nombre a los portales y a los pórticos.

El portal, o portal fondero, se utiliza en las iglesias parroquiales para enmarcar y proteger las puertas de entrada principales.

El pórtico suele recorrer la parte libre del lienzo del mediodía, incluyendo siempre la entrada principal.

Por lo que respecta a sus cubiertas, lo hacen siempre con armaduras. Las más utilizadas son las de colgadizo. Una solución muy utilizada en La Cabrera Alta es el servirse de armaduras molineras en los extremos del pórtico, y de par y nudillo y limabordón en el portal fondero que va siempre en el medio resaltando en altura y produciendo generalmente un armonioso juego de volúmenes. Las armaduras apoyan en pies derechos de madera, que en esta comarca no llevan siempre zapatas.

En todos los pórticos de las iglesias parroquiales hay poyos que unas veces recorren todo su perímetro y otras una parte. Cumplen las finalidades señaladas con anterioridad.

Los cabildos, mantienen la misma función que los pórticos y la única diferencia respecto a los pórticos es que son de fábrica, de cantería.

3.9. Construcciones adjetivas y complementarias: sacristías y osarios

Con el paso del tiempo a las fábricas de las iglesias parroquiales se les añaden otras dependencias: sacristías, osarios, paneras y almacenes que modifican la primitiva estructura del edificio parroquial, pero que en ningún momento lo desnaturalizan ya que siempre, sin excepción alguna, están integrados en el conjunto de forma armoniosa.

Los templos parroquiales medievales rurales nunca tenían sacristía. Se trata de una dependencia que se incorpora más tarde, generalmente a partir del XVI, cuando las iglesias tienen numerosos objetos litúrgicos que guardar y no son suficientes las credencias y las arcas que se disponían en el presbiterio.

En La Cabrera Alta, curiosamente, casi siempre las sacristías se sitúan adosadas a la capilla de la epístola.

En el Antiguo Régimen se enterraba en el interior de las iglesias y cuando estas se llenaban y no había más sepulturas libres, entonces se sacaban los huesos y se guardaban en la propia iglesia, en un espacio adosado a un lateral del pórtico, que recibe diversos nombres, siendo los más comunes los de osarios, oseras y carneros. Todos presentan la misma forma: una especie de arcosolio en el que la parte superior está formada por una pequeña bóveda de medio cañón de buena sillería y bajo él la caja en la que se guardan los huesos, caja que sólo mantiene una abertura por la parte superior, que es por donde se introducen.

\subsection{Los materiales}

La abundancia de materias primas (piedra, madera, arcilla, cuelmo) y su facilidad para conseguirlas posibilitarán en la comarca la autosuficiencia o autoabastecimiento de materiales de construcción. La dependencia y el uso secular de estos materiales pétreos y leñosos autóctonos constituirán su marcado carácter tradicional y popular. 
Según el historiador Vicente Fernández Vázquez, la facilidad para conseguir la materia prima de la construcción, unido a los bajos costes de los salarios, al menos hasta el último tercio del siglo XVIII, junto a la fe, devoción y fervor religiosos y a la necesidad de satisfacer unas necesidades fundamentales en la sociedad del Antiguo Régimen como eran la asistencia a los distintos servicios religiosos (misa, bautismo, enterramiento...) favorecerán el que la mayoría de los pueblos de la zona, por pequeños que sean y por poca población que tengan, levanten sus edificios religiosos (iglesias).

En definitiva, se puede decir que los materiales existentes en La Cabrera condicionarán, la arquitectura religiosa, ya que la utilización de los mismos supondría un notable ahorro para los vecinos y concejo, que son al fin y al cabo los que con el pago de sus primicias, diezmos, enterramientos o "fosarios" y donaciones, hacían posible su construcción, máxime en zonas con una economía de subsistencia que rayaba en la pobreza. $^{10}$

El uso de estos materiales "populares", que en el argot actual denominaríamos "ecológico o sostenible", será sobre todo lo que procure el carácter popular de la arquitectura religiosa cabreiresa.

\subsubsection{Materiales pétreos}

Entre los materiales singulares de la comarca, al margen de esquistos pizarrosos, arcillas, areniscas o cuarcitas que son los materiales pétreos propios de la zona, destaca el uso minoritario, con carácter funcional y ornamental, de la "piedra de Corpora-

\footnotetext{
${ }^{10}$ No hemos de olvidar que el esfuerzo que hacen todos los pueblos cabreireses para construir sus edificios religiosos, en muchas ocasiones está al límite de sus posibilidades económicas. Sería muy difícil, casi imposible, en tales circunstancias económicas, poder hacer algo superior.
}

les". Se caracteriza por su gran resistencia y por su coloración rojiza, consecuencia de la pigmentación de la arcilla y de la presencia de minerales ferruginosos. Una brecha polimíctica ${ }^{11}$ con cemento "ferruginoso" compuesta por clastros ${ }^{12}$ principalmente de pizarra angulosos y calcáreos, y algunos de cuarzo subredondo, todo cementado por cemento ferruginoso y material fino de tono rojo o pardo, que es lo que le da el color ${ }^{13}$.

Para los muros se sirven preferentemente de cuarcitas y esquistos unidos con barro o cal, e incluso, en el caso de los esquistos, según el tipo del que se trate se emplea como sillar, en los muros, siendo su uso generalizado en imafrontes, esquinales, pilares y arcos. Dentro de los esquistos, destaca el uso de la pizarra, para cubrir los tejados, para baldosar los suelos de las iglesias gracias a su facilidad para laminarse en lajas y para los muros. La toba es una piedra calcárea de poca densidad, no muy abundante en la zona, pero que debido a su poco peso se utiliza en arcos, cornisas, vanos.

Asimismo, el canto rodado, prácticamente, es un denominador común en todos los edificios.

\subsubsection{La madera}

La madera, con la piedra, es el material básico de la construcción. Téngase en cuenta que existe una cultura heredada milenaria, desde los romanos, sobre el conocimiento del tratamiento y la manufacturación de la madera. ${ }^{14}$ Con ella se harán

\footnotetext{
${ }^{11}$ Formado por fragmentos de distintas rocas existentes.

${ }^{12}$ Cada uno de los cantos o fragmentos mayores que forman la roca.

${ }^{13}$ Según análisis practicado por Ramón Jiménez Martínez del Instituto Geológico y Minero de España, a quien le agradecemos su ayuda.

${ }^{14}$ M. A. RABANAL ALONSO, León: de astures a romanos, de paganos a cristianos, León, 2009, p. 49. Desde tiempos primigenios existía la creencia que desde la
} 
armaduras de cubierta para cubrir las naves, capillas mayores, sacristías, cabildos o pórticos, y se fabricarán los pies derechos de los pórticos, al margen de vigas, puertas, marcos, suelos...

\section{IGLESIA DE SAN COSME Y DA- MIÁN.}

4.1. Situación geográfica

$\begin{array}{ll} & \text { Coordenadas } \\ \text { Z } & 1.165 \mathrm{~m} \\ \text { X UTM } & 720.396 \\ \text { Y UTM } & 4.684 .276 \\ \text { X Long } & 6^{\circ} 19^{\prime} 38,27^{\prime \prime} \mathrm{W} \\ \text { Y Lat } & 42^{\circ} 16^{\prime} 43,72^{\prime \prime} \\ & \mathrm{N}\end{array}$

\subsection{Descripción}

De todos los edificios religiosos de La Cabrera Alta, el templo parroquial de Pozos es el único que tiene una planta rectangular de tres naves, separadas por dos arcos de medio punto que apoyan en pilares de sección cilíndrica y una portada románica en uso. La nave central es la más ancha, un arco de triunfo separa la capilla mayor, ligeramente irregular y con forma trapecial rectangular, del cuerpo. Flanqueando la capilla mayor se encuentra en el lado del evangelio una capilla que comunica con ella mediante un arco de medio punto, y que está dedicada al Ecce Homo. Al lado de la epístola está la sacristía, a la que se accede por una portada barroca con sus típicas orejeras. Su fábrica es de mampostería, a no ser esquinales, pilares, arcos, vanos, portadas y parte de la espadaña que son de pizarra, arenisca, ... con aparejo de sillar.

luna se regula todo lo relacionado con la vida, la fecundidad de animales y personas y la fertilidad de la tierra y vegetación. De acuerdo con esta regulación se siembra en luna creciente, para que el grano fructifique bien y se cortan los árboles para madera de construcción en luna menguante, y en invierno, cuando menos savia o casi ninguna circula y así su duración es más larga.
Las naves han sido recubiertas por una falsa bóveda, y las capillas del evangelio y del presbiterio conservan las armaduras fabricadas en el año 1777, según como consta en la inscripción cuádruple de las pechinas con las pinturas de san Juan (AÑO), san Mateo (DE), san Marcos (1000) y san Lucas (771), o sea, "AÑO DE 1.771". La primera, dedicada al Ecce Homo, es de tres paños con forma de ochavo, de par y nudillo con gualderas ataujeradas y de limabordón nones con unos 4,50 m de luz y el arrocabe con estribo visto.

Toda ella conserva la pintura original compuesta por la imitación en cada una de las partes del ochavo de placas en cuyo interior se representan los símbolos de la pasión de Cristo en clara referencia a la titularidad de la capilla.

La del presbiterio, es semejante a la de la capilla del Ecce Homo, ya que las dos son hechas en las mismas fechas y por el mismo artesano al presentar las mismas características técnicas, formales y estilísticas. Se trata de una armadura de tres paños que responde al tipo constructivo de par y nudillo también con gualderas ataujeradas y de limabordón nones diferenciándose solamente en el tamaño, ésta es de $6 \mathrm{~m}$. de luz, el arrocabe formado por aliceres simples con el estribo oculto y en la presencia en las esquinas de cuatro pechinas colgantes entabladas. Al igual que la otra, ésta también está primorosamente pintada con placas rectangulares de colores en los que predominan los rojos, azules y color hueso entre los que se mezclan algunos temas de la Pasión, mientras que en las pechinas, retratos de los cuatro evangelistas rodeados de flores y de jarrones ${ }^{15}$.

Al exterior, destacan la armonía de todo el conjunto, la calidad de su construcción, el buen estado de conservación y muy

\footnotetext{
${ }^{15}$ M. FERNÁNDEZ CABO, Op. cit. p. 130.
} 
especialmente su portada románica construida en sillar con piedra arenisca formada por unas pilastras con bocel y doble chaflán al exterior y acabaladas al interior sobre el que se sitúan las impostas corridas sobre las que apoyan las dovelas del arco con bocel completo al exterior y de cuarto de bocel, al interior y con la chambrana decorada con doble acanaladura en el centro. Es de destacar la presencia en su base de motivos decorativos de carácter vegetal, entre los que sobresalen varias flores de lis. Sobre la clave del arco se encuentra una inscripción conmemorativa de la consagración de la iglesia, sobre piedra arenisca y en mal estado y escrita en letra carolina, pero cuya trascripción ha llegado a nuestros días gracias a la copia que en el año 1761 realizó el párroco de Pozos, Martín Blanco, y que dice así: "Pelagius Petri fecit acclesiam istam anno ab incarnatione domini milesimo CC XXX Vo Era Milesima CC(a). LXXIII (a) X kalendas madii consacrata per Nunun astoricenssem episcopum fuit ecclesia de Pozos ad honorem beati Cosme et Damiani et beate Marie et Sancti Francii", cuya trascripción sería la siguiente: "Pelayo Pérez hizo esta iglesia. El año de la Encarnación del Señor 1235, era 1273, el día diez de las kalendas de mayo fue consagrada esta iglesia de Pozos (falta) por Nuño, obispo de Astorga, en honor de los Bienaventurados Cosme y Damián y de la Bienaventurada María y san Francisco"16.

Finalmente, significar la presencia de la espadaña, a la que le falta el remate, por lo que termina en una cornisa recta y a la que se accede por medio de una escalera exterior construida en la prolongación del muro occidental por su parte septentrional

${ }^{16}$ J. NuÑo GONZÁlez, "Pozos. Iglesia de San Cosme y Damián", en M. A. GARCía GUINEA y J. M. PÉreZ GONZÁLEZ (Dir.), Enciclopedia del Románico en Castilla y León. León, Aguilar de Campoo, 2002, p. 376.

\subsection{Historia constructiva}

La fábrica actual, a excepción de los elementos señalados y parte del muro del lado del evangelio, responde a momentos muy posmedievales, ya que se trata de obras realizadas en los siglos XVII y XVIII. Creemos que la iglesia actual sería la tercera que se construye en el mismo solar, ya que primero hubo una en el siglo XII, tal y como lo evidencia las referencias documentales que aluden a su existencia al menos en en el año 1165 cuando el rey de León dona al monasterio de Peñalba la iglesia de San Cosme de Pozos ${ }^{17}$. La segunda, sería la que se reedificó en el XIII (momento en el que se consagra de nuevo como lo manifiesta la inscripción de la portada del mediodía a la que hemos hecho refrencia anteriormente) y la tercera, obra ya del siglo XVII.

De la primera solamente se conserva la portada principal. El estilo de la portada concuerda perfectamente con las formas románicas del siglo XII y no se puede considerar del siglo XIII, de la época de la inscripción, argumentando como hacen algunos autores ${ }^{18}$ que responde a la pervivencia de arcaísmos presente en ámbitos alejados y máxime cuando esta iglesia de Pozos está a tan solo $43 \mathrm{Km}$. de La Bañeza. Por la inscripción medieval, colocada sobre la clave de la portada románica del siglo XII, conocemos que esta iglesia de San Cosme y San Damián se consagró en el año 1235.

El hecho de que se consagrase no quiere decir que obligatoriamente hayamos de juzgar que se trate de un nuevo edificio, porque muy bien puede tratarse de una reedificación. Esta primitiva iglesia románica del XII y redificada en el XIII, presentaría una sola nave y un ábside semicircular con

\footnotetext{
${ }^{17}$ P. RODRÍGUEZ LÓPEZ, Episcopologio Asturicense, vol. II, Astorga, 1907, p. 215-216.

${ }^{18}$ J. ÑuÑO GONZÁLEZ, Op. cit., p. 376.
} 
tramo recto ${ }^{19}$. En el siglo XVII cuando se construye la nueva capilla mayor se hace sobre el espacio medieval formado por el tramo recto y el ábside semicircular, que no mantiene ya esta forma sino que se transforma en rectangular, propio del momento. Tal y como podemos comprobar las relaciones planiméricas de esta primitiva iglesia románica concuerda con las de la provincia leonesa, estudiadas por María Concepción Cosmen $\mathrm{Alonso}^{20}$, ya que el parámetro de la relación entre la longitud de la nave respecto a su ancho es de 2,5; mientras que la relación entre la longitud total del edificio (planta y ábside) y la longitud del ábside es de 3. Relaciones planimétricas semejantes a la mayoría de los edificios románicos de la diócesis.

En 1771, como ya se ha demostrado, se hacen las dos armaduras de cubierta del presbiterio y de la capilla del evangelio y unos pocos años más tarde, en 1793, se edificó la torre actual, tal y como figura en la inscripción epigráfica situada en el muro lateral del sur junto al reloj de sol de pizarra; un sencillo y hermoso reloj que Francisco Martínez hizo en el año 1776 (ver ilustración).

\section{CONCLUSIONES}

En el presente trabajo se puede concluir que:
5.1. La elección del proceso metodológico y el análisis tipológico seguido, en relación con otras arquitecturas vecinales, ponen de relevancia la conveniencia para obtener la restitución gráfica evolutiva desde su fundación, s XII, hasta derivar en la articulación de la forma arquitectónica final.

5.2. La definición geométrica de la planta de estos lugares era de composiciones cuadradas y rectangulares, articuladas mediante un eje longitudinal, generalmente, este-oeste. El pórtico mantiene orientación meridional.

5.3. El conjunto, atendiendo a su funcionalidad, responde a una tipología compuesta por diversos volúmenes que forman el espacio interior del templo; las dependencias complementarias se adosan a sus muros.

5.4. La comarca ofrece en la actualidad uno de los paisajes culturales más auténticos de la península. La iglesia de Pozos forma parte de un paisaje cultural que sobrevive a la naturaleza. El número de edificios religiosos en función de los asentamientos de población es escaso. Está en manos del hombre preservar la primitiva Cabrera.

\footnotetext{
$19 \overline{\text { Al igual que la mayor parte de las iglesias románi- }}$ cas del siglo XII de la provincia leonesa.

${ }^{20}$ M. C. COSMEN AlONSO, El arte románico en León. Diócesis de Astorga, León, 1989, p. 69.
} 


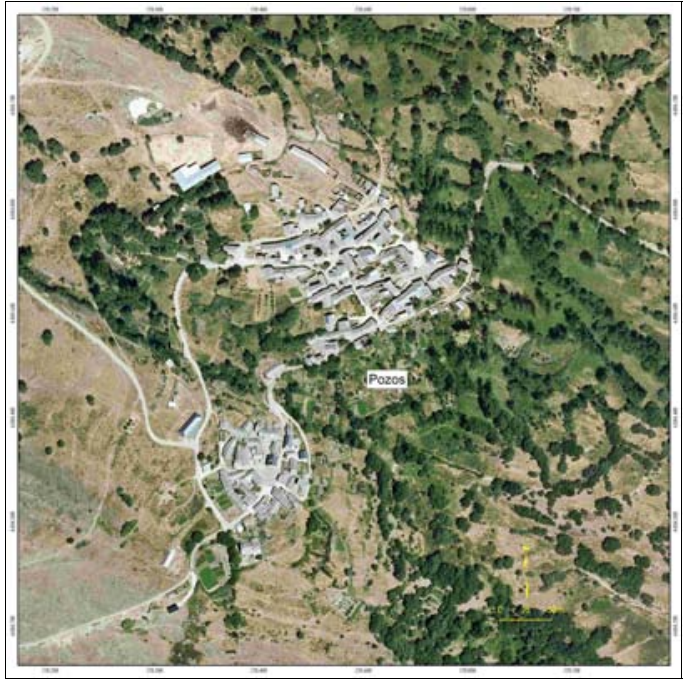

- Fig 1. Ortofoto del pueblo de Pozos.

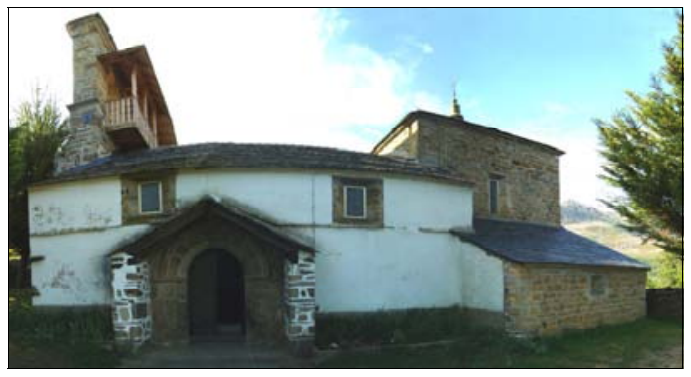

- Fig 3. Panorámica cilíndrica correspondiente a la fachada con orientación meridional.

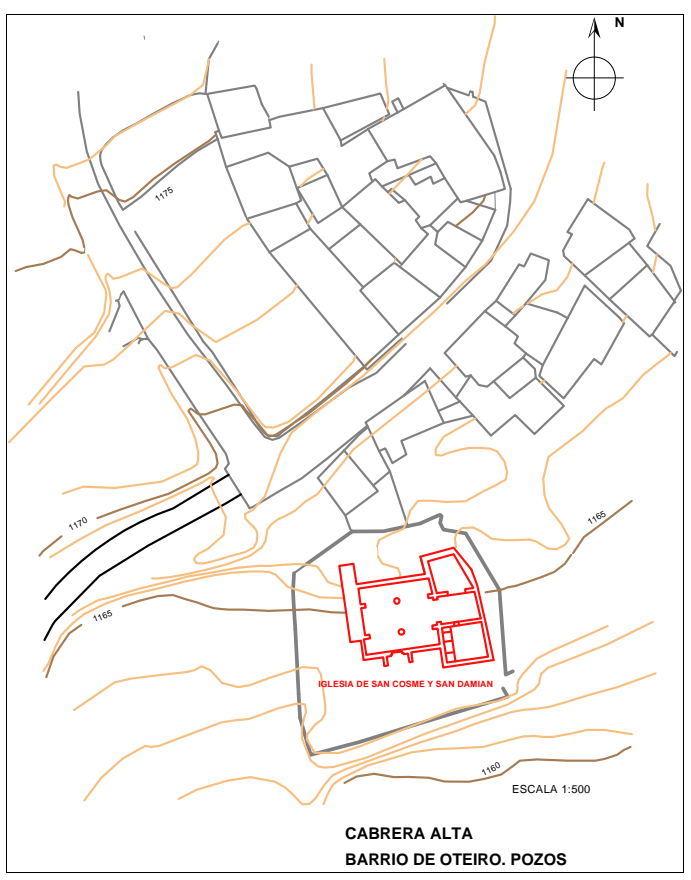

- Fig 2. Plano topográfico del emplazamiento de la iglesia al sur del barrio de Oteiro y separada del término municipal.

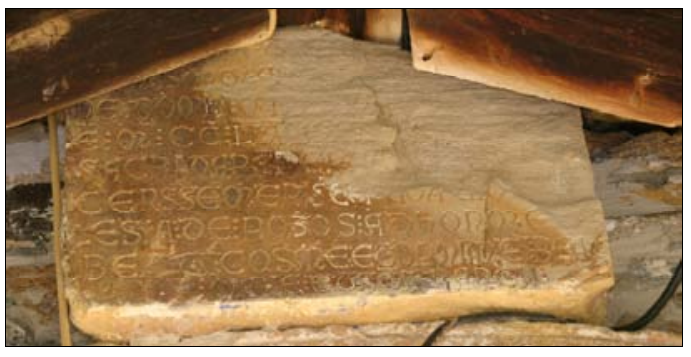

- Fig 4. Documento epigráfico, situado sobre la clave del arco, conmemorativo de la consagración de la iglesia.

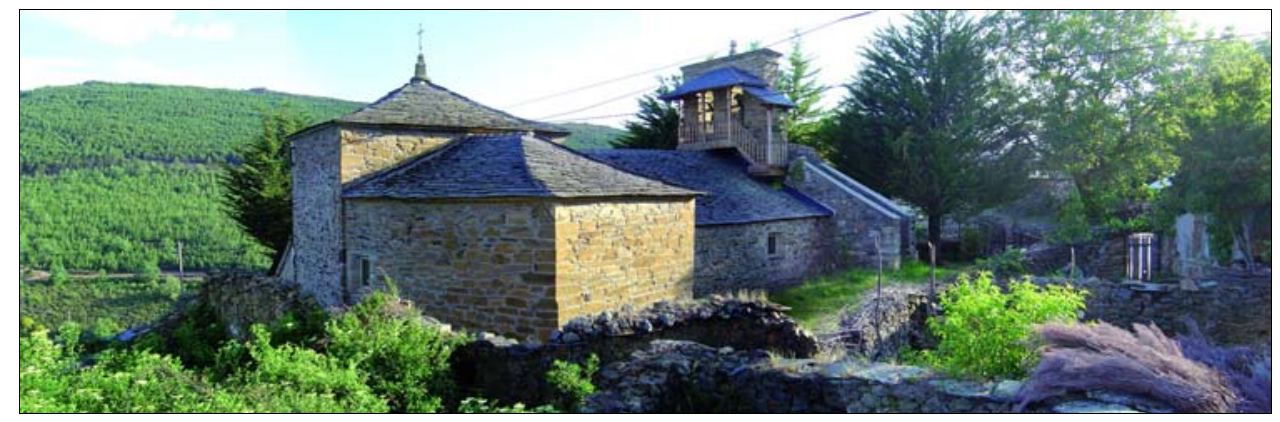

- Fig 5. Panorámica nordeste de la iglesia. 


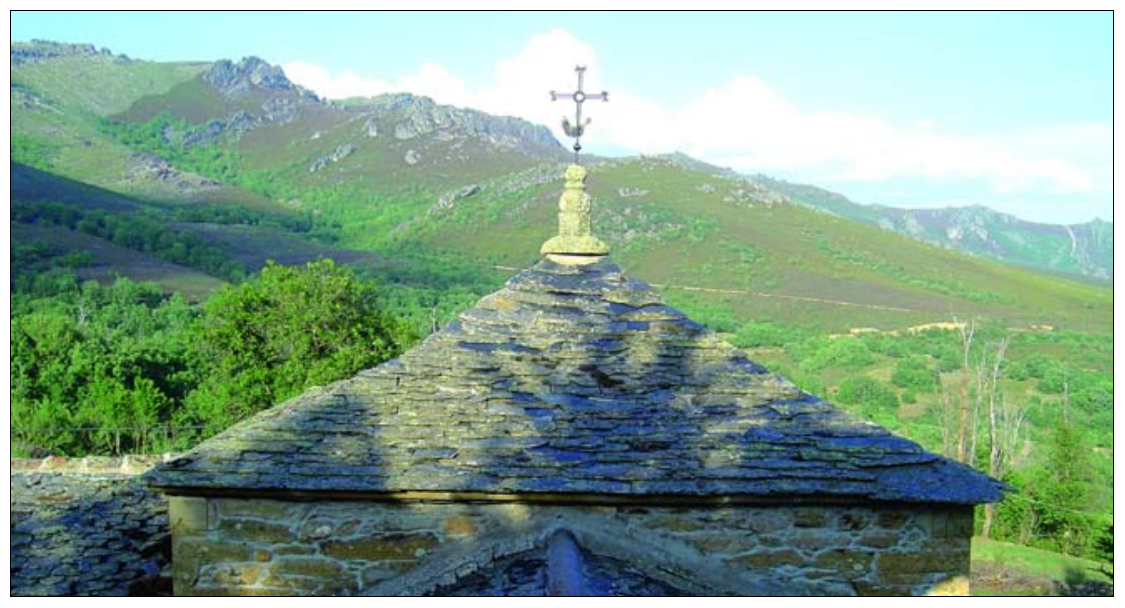

- Fig 6. Iglesia de Pozos. Cubierta de losas de pizarra a dos, tres y cuatro aguas.

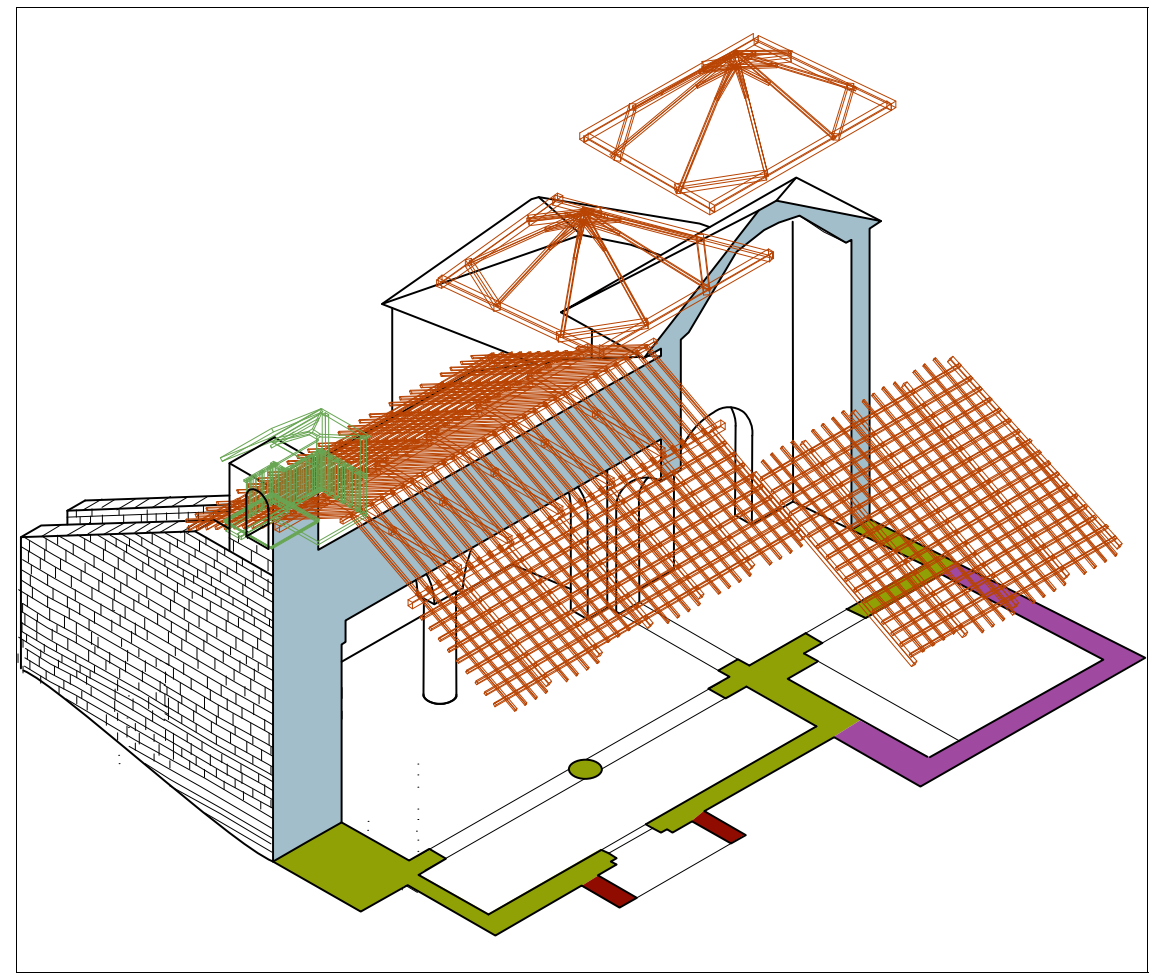

- Fig 7. Perspectiva explosionada con sección longitudinal de la iglesia de Pozos. 

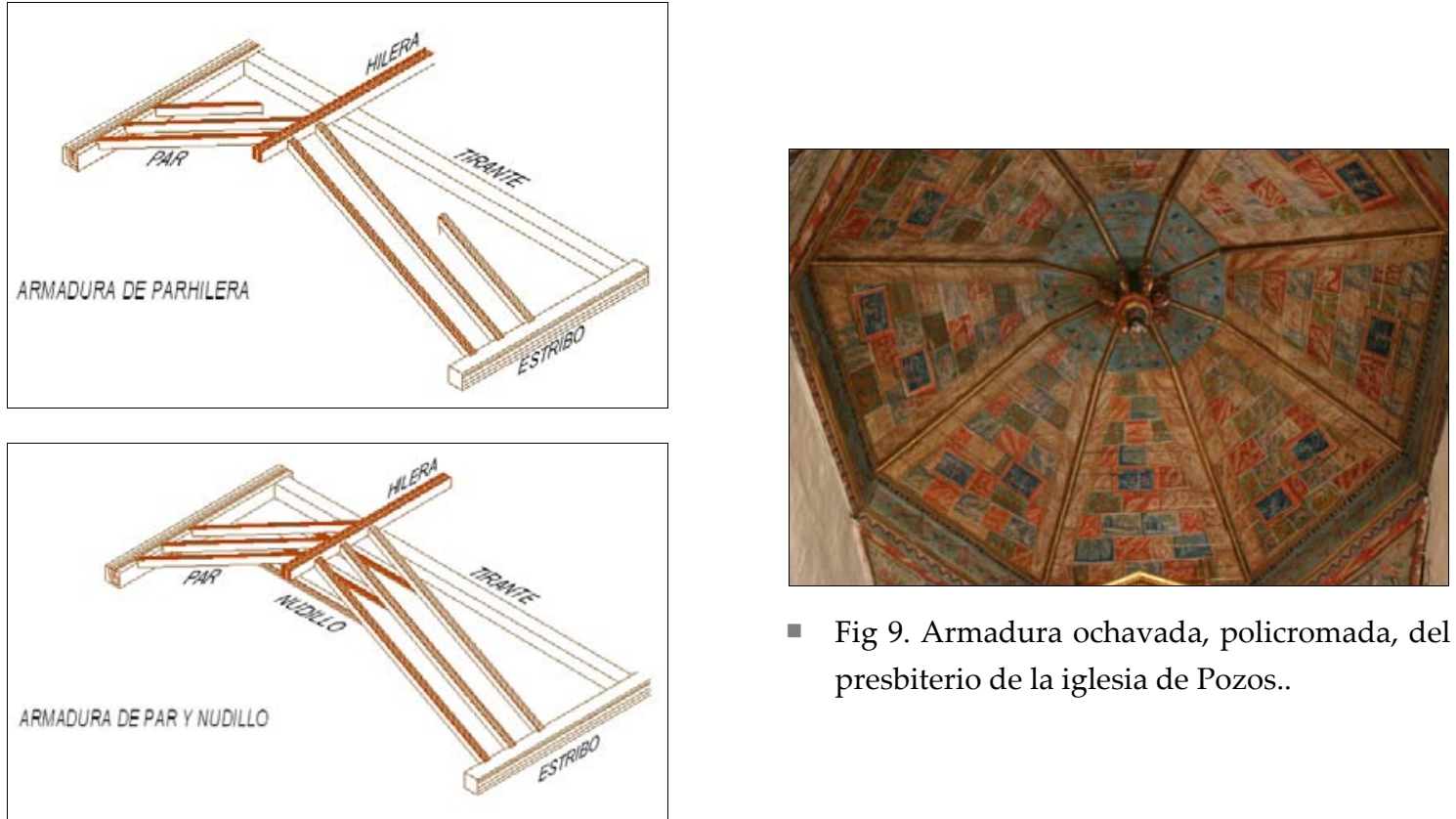

- Fig 9. Armadura ochavada, policromada, del presbiterio de la iglesia de Pozos..

- Fig. 8. Tipología de armaduras de pares más frecuentes.

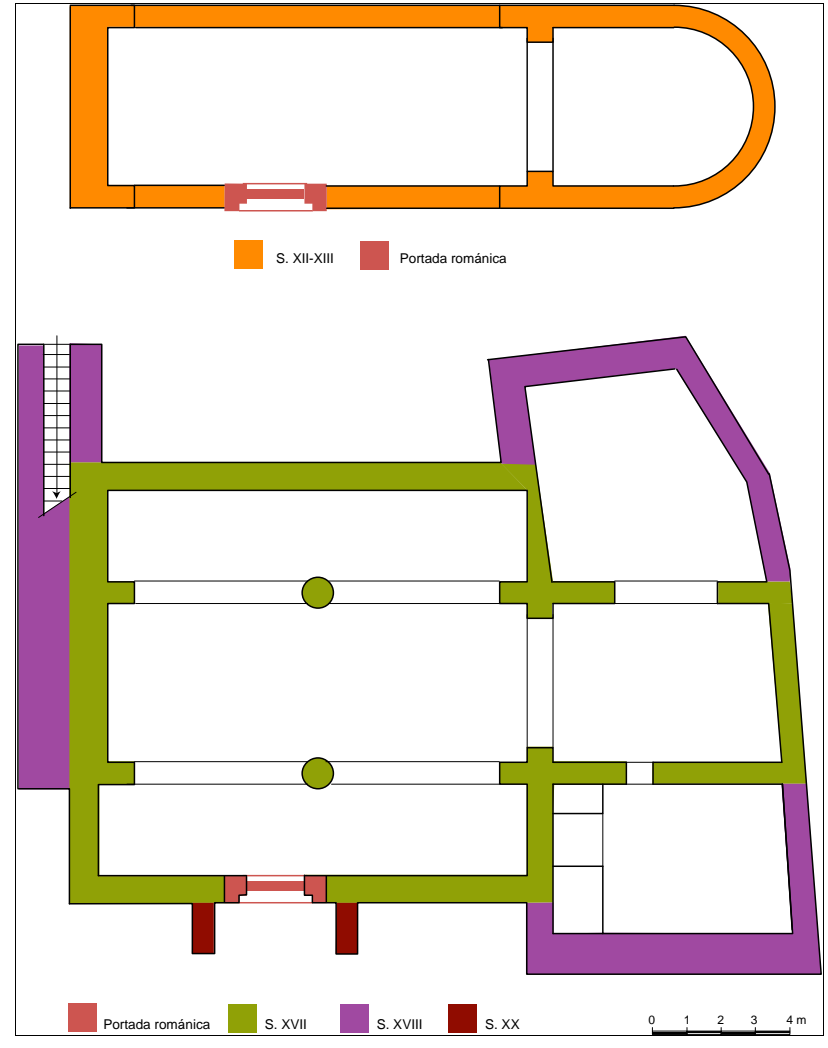

- Fig 10. Planimetría histórica evolutiva. 


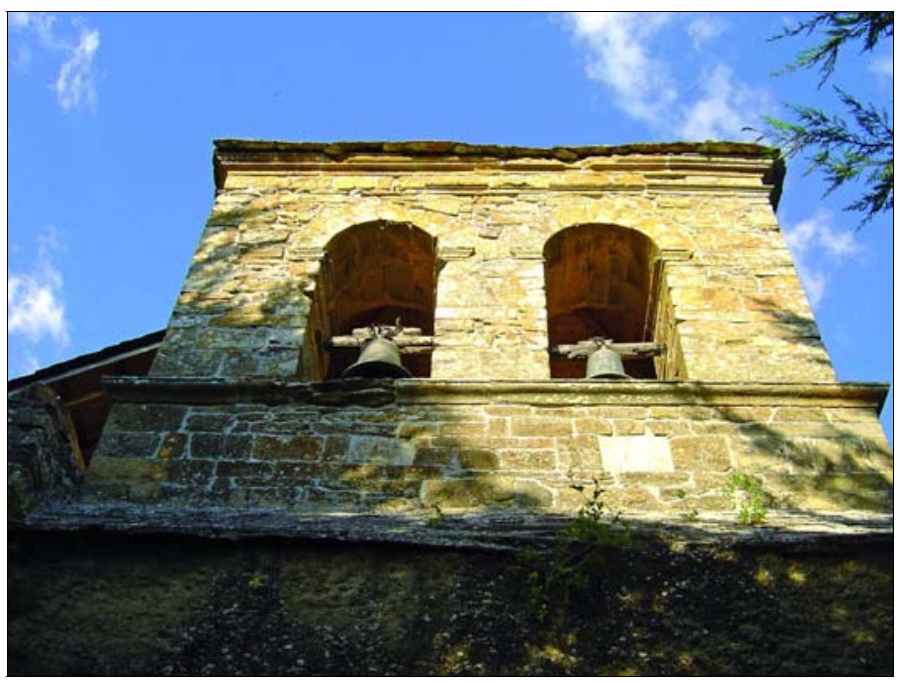

- Fig 11. Pozos. Espadaña protegida con cornisa recta.

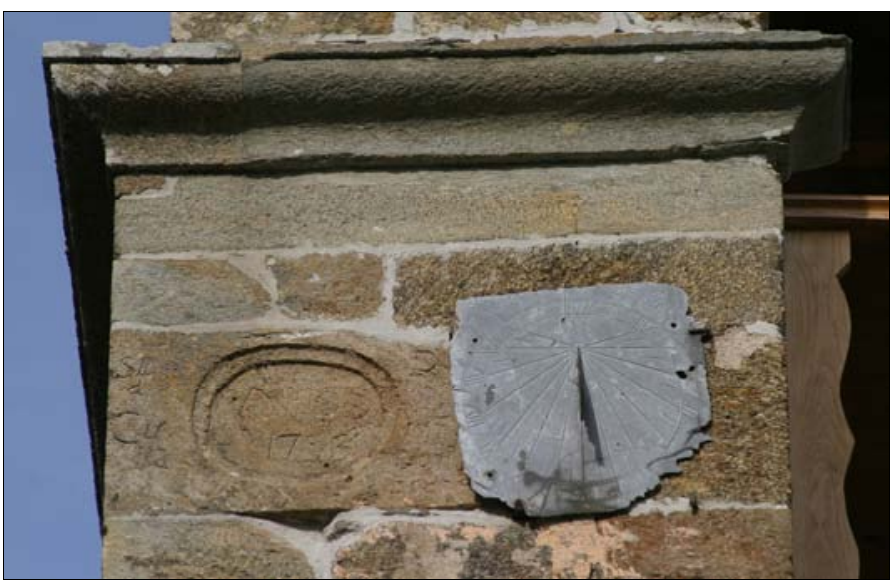

- Fig 12. Documento epigráfico justificatico de la construcción de la torre en 1793. A su derecha el reloj solar, único que se conserva sobre pizarra. 